\title{
Improved indoor lighting improved healthy aging at home - an intervention study in 77-year-old Norwegians
}

This article was published in the following Dove Press journal: Journal of Multidisciplinary Healthcare

\author{
Helle K Falkenberg $\mathbb{D}^{\prime}$ \\ Tor Martin Kvikstad (iD ${ }^{2}$ \\ Grethe Eilertsen (iD ${ }^{3}$ \\ 'National Centre for Optics, Vision and \\ Eye Care, Department of Optometry, \\ Radiography and Lighting Design, \\ University of South-Eastern Norway, \\ Kongsberg, Norway; ${ }^{2}$ Department of \\ Business, Strategy and Political Sciences, \\ University of South-Eastern Norway, \\ Kongsberg, Norway; ${ }^{3}$ USN Eldreforsk \\ Research Group, Department of \\ Nursing- and Health Science, University \\ of South-Eastern Norway, Kongsberg, \\ Norway
}

Introduction: Healthy aging and good quality of life is important to allow older people to live at home. Lighting is a significant environmental attribute promoting visual, physical, and mental health. Due to normal visual age changes, older people need more light, but improving indoor lighting levels receives little attention.

Objective: To investigate the impact of improved home lighting on abilities to perform activities of daily living (ADLs) and quality of life in healthy older people.

Methods: Sixty healthy 77 years old living at home participated during the 4-month dark winter period. In the intervention group ( $I G, n=30)$, the living room lighting was optimized by providing lamps and a basic control system with three preset levels (normal, medium, low). Participants chose the light level and kept a diary. No change was implemented for the control group $(C G, n=30)$. A questionnaire measured self-reported visual and general health and ability to perform ADL in regards to lighting before and after the intervention in both groups.

Results: In the IG, lighting levels significantly improved self-assessed lighting levels, abilities to perform ADLs, and read and write in the living room (all $p<0.03$ ). In the CG the only change was a deterioration in performing ADLs $(p<0.05)$. The difference in change was significant between the IG and CG (all $p<0.02$ ). "Normal" lighting was the preferred level and increased comfort and well-being. The IG also resumed visually demanding tasks, and acknowledged that avoiding these tasks were mainly due to poor lighting.

Conclusions: Good vision is essential in promoting healthy aging at home and require adequate lighting. This can easily be achieved using a basic light system. Adopting to higher lighting levels evolves quickly. Our results suggest that improved quality of light could improve quality of life, and lighting should be included as a factor promoting healthy aging at home.

Keywords: home environment, older people, aging, vision, health promotion, lighting intervention

\section{Introduction}

Increased life expectancy and improved living conditions in combination with an escalating older population with health care needs will lead to great challenges in Norway and internationally. ${ }^{1-3}$ Arranging for people to remain living at home as long as possible may result in both improved quality of life, health and significant social economic effects. ${ }^{4}$ Healthy aging is defined by the WHO as "the process of developing and maintaining the functional ability that enables wellbeing in older age." ${ }^{5}$ Functional ability is influenced by both environmental and individual capacities. Good vision is important to enable living at home and performing everyday tasks. Due to normal age-related vision loss, older people
Correspondence: Helle K Falkenberg National Centre for Optics, Vision and Eye Care, Faculty of Health and Social Sciences, University of South-Eastern Norway, Hasbergs vei 36 , Kongsberg 3616 , Norway

Tel $+473 \quad 1008961$

Email helle.k.falkenberg@usn.no 
need correct glasses and more light to perform daily activities efficiently and safely. Reduced vision negatively effects general health and basic activities of daily living (ADLs, eg, dressing, transferring) and instrumental activities of daily living (IADLs, eg, reading ${ }^{6}$ ). Poor vision is associated with an increased risk of trips and falls, often resulting in fractures and other injuries, ${ }^{7-10}$ feelings of loneliness, depression, and anxiety. ${ }^{9,11-15}$ Poor lighting exacerbates these problems, and older people commonly report difficulties reading in dim light and are only able to drive during the day. ${ }^{16-19}$ Insufficient and poor lighting increase the risk of fall accidents among older people. ${ }^{20-23}$ Lighting is thus a significant environmental factor promoting visual, physical, and mental health, ${ }^{24-26}$ enabling successful aging at home. This was found more than 20 years ago, when Sörensen and Brunström showed that improved indoor lighting increased the quality of life in healthy older people living at home. ${ }^{27}$ Since then, however, the need for more light to promote healthy aging at home, and to compensate for normal age-related vision loss, has received little attention in both the older population ${ }^{28-32}$ among health care personnel, ${ }^{19}$ and public health agencies. ${ }^{4}$ The focus of lighting research has been on therapeutic effects of lighting in nursing homes and in clinical populations, such as those with dementia, depression, seasonal disorders, sleep disorders, and low vision. ${ }^{33-38}$

The intervention described in this study is part of a larger study, where we previously have described the indoor home lighting levels, self-reported vision and general health, and ADLs in 114 healthy 75-year-old Norwegians. ${ }^{31}$ Despite very low levels of indoor lighting, the participants were happy and healthy. We also found a large discrepancy between self-assessed health and recommended lighting levels, and low awareness of the effect of lighting on age-related vision loss or daily activities in the future. Consequently, the aims of the intervention were to investigate how improved lighting effected abilities to perform ADLs and health-related quality of life in healthy older persons living at home.

\section{Methods}

\section{Design}

This intervention study forms Stages II-V of a study exploring how indoor lighting effects vision, health, ADL, and quality of life in healthy older persons living at home (see Figure 1).

\section{Setting}

The intervention took place in the living room in the private homes of healthy older persons living in the
Southeast of Norway. The living room was chosen because this is where older people spend most of their waking hours, performing both hobbies, ADLs, IADLs, and social activities/interactions with friends.

\section{Sample}

The intervention was planned for two groups of 30 (Figure 1, Stage II) of the participants with the poorest living room lighting levels in Stage I. ${ }^{31}$ The 77 -year-old participants were stratified according to gender, housing, and cohabitancy (based on results from Stage $\mathrm{I}^{31}$ ) to ensure equal allocation in the intervention group (IG) and the control group (CG), before being randomly assigned to one of the groups (Figure 1, Stage III). Exclusion criteria were recipient of any public health care, the presence of obvious cognitive impairment or palliation as documented in the medical journal or by clinical judgment by the health preventative nurse team (HPNT). Sociodemographic characteristics are presented in Table 1.

\section{Intervention (Stages III-V)}

Figure 1 describes the 4-month intervention which occurred during the dark winter period (October-February) to avoid influence from natural daylight (Stages III-V). At the start and end of the intervention (Stages III and V) both the IG and CG self-reported visual and general health, and ability to perform IADLs in regards to lighting using a questionnaire. ${ }^{31}$ In Stage IV, the lighting was optimized by 1) measuring light levels and supplementing existing lamps if necessary to achieve recommended living room lighting levels (200 lux) for older persons, ${ }^{39}$ and 2) installing a wireless control system with three preset levels. During the intervention period, the IG kept a diary where they documented the amount of hours they used each of the three preset light levels.

\section{Aspect on designing a successful home lighting intervention (Stage IV)}

The intervention required evaluation of and physical change (adding lamps and control system) to the living room and private homes of older persons. To achieve a successful intervention, several aspects were important to consider. $^{39,40}$ The intrusion to the participant's personal taste and interior had to be minimized, and both added lamps and the control system needed to be as inconspicuous as possible and not require permanent installations. Both lamps and the control system needed to be commercially available and universally designed. In collaboration with the lighting designers, the following criteria was required 


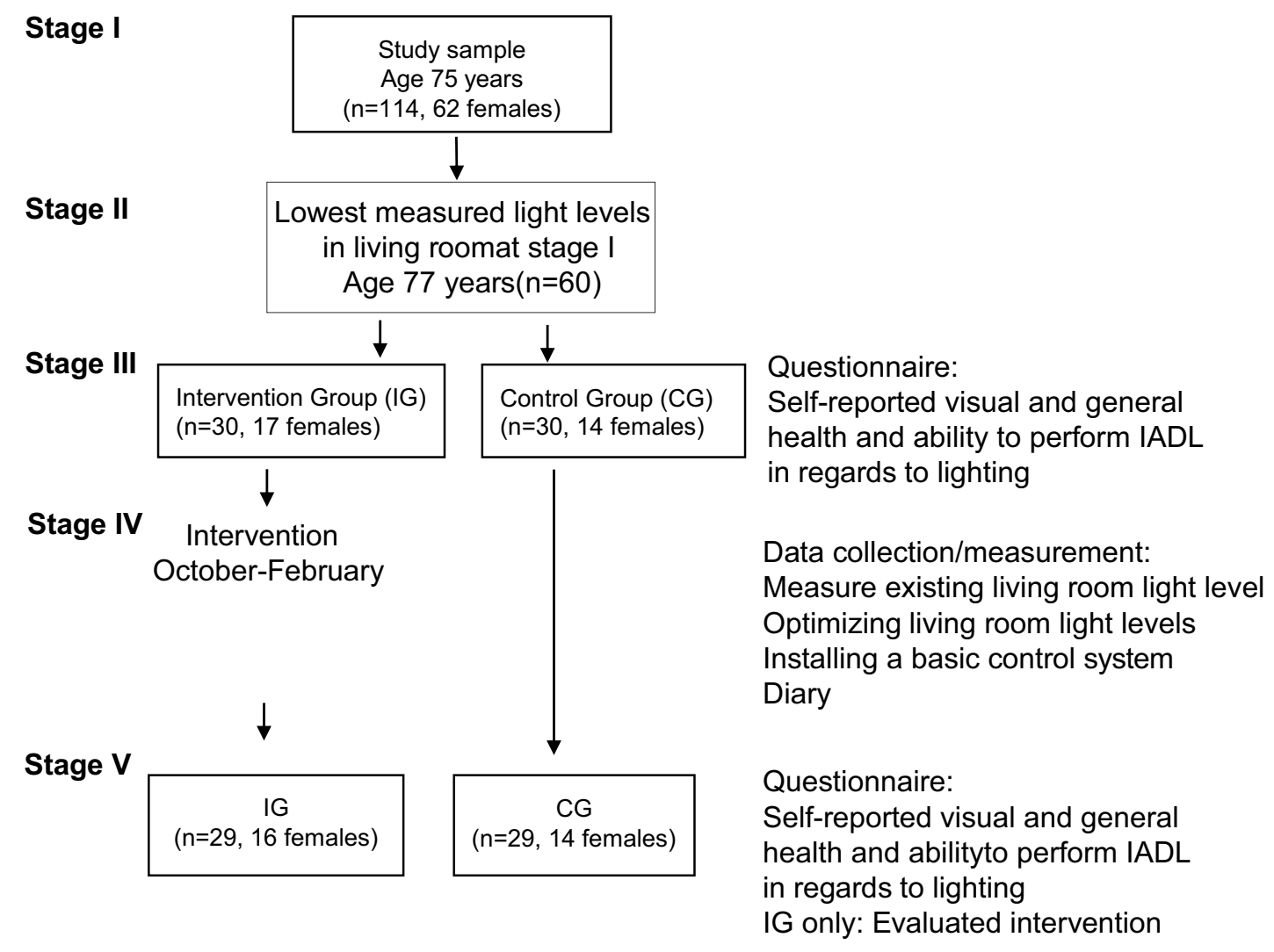

Figure I Flowchart describing the stages of the study, the intervention is described by Stages II-V. The baseline Stage I is described elsewhere. ${ }^{3 \mathrm{I}}$

Table I Sociodemographic characteristics of the 77-year-old participants in the intervention and control group at Stage III and participants in the baseline study at Stage I

\begin{tabular}{|c|c|c|c|c|}
\hline Variable & & $\begin{array}{l}I^{\prime} \mathbf{G}^{\mathbf{a}} \\
\mathrm{n}=30\end{array}$ & $\begin{array}{l}C^{C} G^{b} \\
n=30\end{array}$ & $\begin{array}{l}\text { Baseline }^{c} \\
\mathrm{~N}=\text { I I } 4\end{array}$ \\
\hline \multirow[t]{2}{*}{ Gender } & Female & 17 & 14 & 62 \\
\hline & Male & 13 & 16 & 52 \\
\hline \multirow[t]{2}{*}{ Housing } & Detached house & 13 & 13 & 35 \\
\hline & Apartment/semi-detached & 17 & 17 & 78 \\
\hline \multirow[t]{2}{*}{ Marital status } & Married/cohabitant & 17 & 15 & 69 \\
\hline & Unmarried/not cohabitant & 13 & 15 & 44 \\
\hline \multirow[t]{2}{*}{ Ethnic origin } & Norwegian & 29 & 29 & 110 \\
\hline & Danish & I & I & 4 \\
\hline \multirow[t]{2}{*}{ Income } & High $(>39000 €)$ & 16 & 14 & 64 \\
\hline & Low $(\leq 39000 €)$ & 13 & 14 & 44 \\
\hline \multirow[t]{2}{*}{ Education level } & More than compulsory school & 10 & 8 & 31 \\
\hline & Compulsory school & 19 & 22 & 82 \\
\hline
\end{tabular}

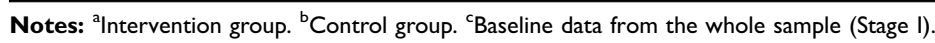

for all lamps: energy efficient, tolerate a $40 \mathrm{~W}$ light bulb, minimum level of glare, bulbs easy to replace, and reasonable cost and design. The participants (IG) chose from the preselected range of floor and table lamps. The control system was chosen upon fulfilling the following criteria: wireless, easy to use, programmable light levels, and reasonable cost and design. The control system connected up to seven lamps, and enabled three preset levels of lighting. In 
this intervention, we programmed three options: 200 lux (normal); 100 lux for watching TV (medium); and 50 lux for "candlelight dinner" (low). In addition, an "off" button turned off all the lamps connected to the control system. After a brief instruction, the participants found the control system easy to use.

\section{Questionnaire (Stages III and V)}

All participants reported sociodemographics, IADLs with respect to indoor lighting levels, symptoms of visual problems and general health-related quality of life (SF 36) in a questionnaire ${ }^{31}$ with 55 questions including free comments. VASs were used to self-report on the ability to perform IADLs and visual health. VAS comprises a $100-\mathrm{mm}$ horizontal line whose endpoints represent the positive and negative extremes pertaining to a particular statement, and the respondent marks the position that best represented their level of agreement with the statement. General healthrelated quality of life was assessed using SF-36 (Norwegian version $1.2^{41}$ ) with 36 items that assess eight health scales (physical and social functioning, general and mental health, role physical and emotional, bodily pain, vitality, and health transition) over the past year. The physical health summary measure (PH) and mental-health summary ( $\mathrm{MH})$ measure are aggregated from the health scales. ${ }^{42}$ The questionnaire took approximately 45 mins to complete, and all completed the questionnaire during a visit by the HPNT at Stages III and V. At the completion of the study (Stage V), the IG additionally assessed the lighting intervention answering eight questions, including a free text comment.

\section{Light measurements (Stage IV)}

The living room lighting optimization in the IG took place during the dark winter months (Stage IV). Lighting designers measured the lighting levels $80 \mathrm{~cm}$ above floor level in a $1 \times 1-\mathrm{m}^{2}$ grid, according to international standard procedures. ${ }^{31,43}$ The baseline study ${ }^{31}$ showed that the average living room lighting level was just 35 lux, well below the recommended level of 200 lux. $^{39}$ If the recommended lighting level could not be achieved with existing lamps, extra lamps were added. Lamps were connected to the wireless control system. Participants were encouraged to use the "normal" level as this ensured the recommended 200 lux. The lighting designers also gave advice on good lighting conditions, ie, the position and direction of light, use of daylight, color and contrast, and to avoid glare. ${ }^{39,44}$ After 1 week, participants were contacted to ensure that everything was working, and to answer any questions.

\section{Data analysis}

Continuously distributed location variables are presented as means with standard deviations. Because of very skewed distributions and small groups, nonparametric tests were used. Even if a few distributions indicated the use of Student's $t$-test, we chose to use nonparametric test all over to avoid confusion. Differences between groups were tested using a Wilcoxon rank-sum test (Mann-Whitney test). For paired sample tests, Wilcoxon signed-rank test was used. All tests were twotailed using the null hypothesis of equality. In some comparison of the two groups (IG and CG) involving counts, binominal tests were used. To compare more than two related samples, Friedmans' test was used. The threshold for statistical significance level was set at $5 \%(p<0.05)$. All computations were performed using the statistical package SPSS Statistics 25 (International Business Machines, USA).

\section{Results}

After completing the questionnaire at Stage III, one participant in the IG withdrew from the study and one in the CG did not complete the final questionnaire. These two were excluded from the final analysis.

A typical living room measured about $30 \mathrm{~m}^{2}$. At the beginning of the intervention (Stage IV), the lighting designers added lamps to 26 living rooms to achieve the recommended lighting levels. The IG group reported significant larger improved ability to perform IADLs than the CG (mean difference between groups of $11.7 \mathrm{~mm}$, $p=0.003$ ). For reading and writing in the living room a mean difference of $12.3 \mathrm{~mm}$ was reported with $p=0.006$ and at the dining table (mean difference between the groups of $4.8 \mathrm{~mm}, p=0.019$ ). Table 2 shows the change in perceived indoor lighting environment, ability to perform IADLs and general health for the IG and CG between Stage III and Stage V. The IG group reported large and significant improvements in the self-assessed indoor lighting levels (mean improvement of $21.9 \mathrm{~mm}, p<0.001$ ). They also reported an improved ability to perform IADLs (mean improvement of $8.8 \mathrm{~mm}, p=0.026$ ), including reading and writing in the living room (mean improvement of $12.3 \mathrm{~mm}, p<0.001$ ) or at the dining table (mean improvement of $3 \mathrm{~mm}, p=0.016$ ). The only change in the CG was a significant deterioration in the ability to perform IADLs (mean deterioration of $2.9 \mathrm{~mm}$, Wilcoxon, $p<0.022$ ). Further, the IG reported an improvement in 24 


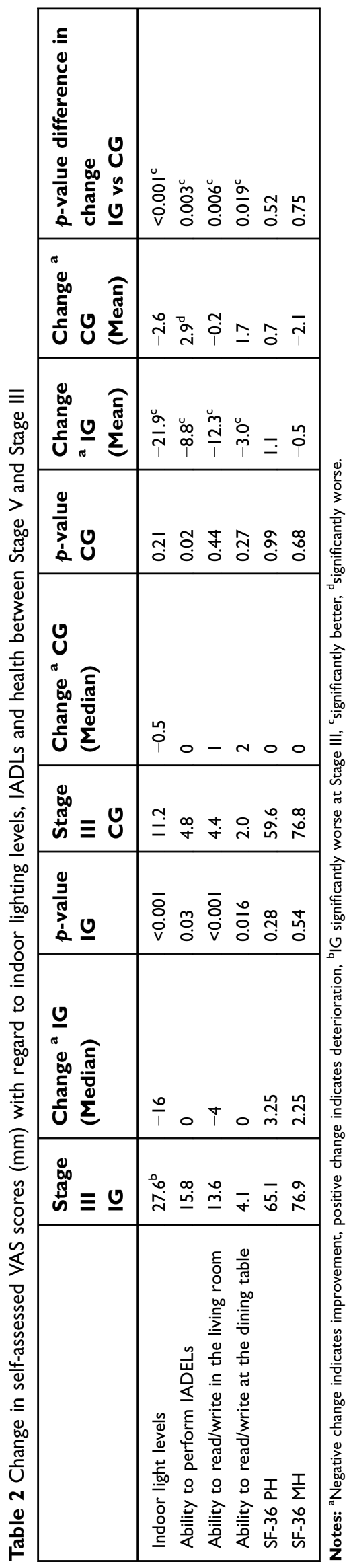

of the 28 items asking about the ability to perform ADLs. This was statistically better, compared to the CG $(p<0.001)$. Self-reported visual problems and health remained unchanged in both groups during the 4-month intervention (all $p>0.05$ ). The SF-36 mean PH scores for the IG and CG were 63.6 and 58, respectively, and 75.6 and 76.9 for mean MH scores. The SF-36 scores remained the same, and there was no difference within or between the two groups (all $p>0.05$ ).

All participants kept a diary documenting how the three preset light levels were used for each day. Figure 2 shows the total sum of hours used with the different light levels during the intervention period. As can be seen, the "normal" level is the preferred light level during the intervention period compared to the two lower light levels $(p<0.001)$. For all light levels the number of hours used peaked in the middle of the period, and tailors off at the start and end of the intervention. Further, there is a small drop around 75-85 days, coinciding with the Christmas and New Year holiday period.

With regards to the use of "normal" lighting, the proportion of persons who use this for a long time (5-8 hrs per day) is significantly increasing during the intervention period $(p<0.001)$. This is at the expense of the proportion who use it for shorter periods, which subsequently are decreasing.

After the intervention, 26 answered eight questions assessing the two intervention elements. Overall, their assessment showed that most were very satisfied with both the lighting and the control system. Twenty-two participants were very satisfied or satisfied with increased lighting levels, 21 were very satisfied or satisfied with the preset levels, and 23 reported to be very satisfied or satisfied with the control system. When asked to assess the importance of the different criteria applied to choose lamps and control system to include in the intervention, the ease of replacing bulbs, that lamps prevented glare and that the control system was easy to use was considered very important by 18,19 , and 19 , respectively, and 4,1 , and 2 said it was important. The ability to use energysaving bulbs and the cost of lamps or control system was considered very important by 12,12 , and 13 , and not important by 5, 4, and 5, respectively. Comments from the free text were almost exclusively positive regarding the improved lighting. Several reported that they now realized that before the intervention, their lighting levels were poor leading to reduced visual ability. With the improved lighting, they were now able to resume some meaningful activities they had stopped performing due to poor lighting and vision. One commented that they used more light now, 


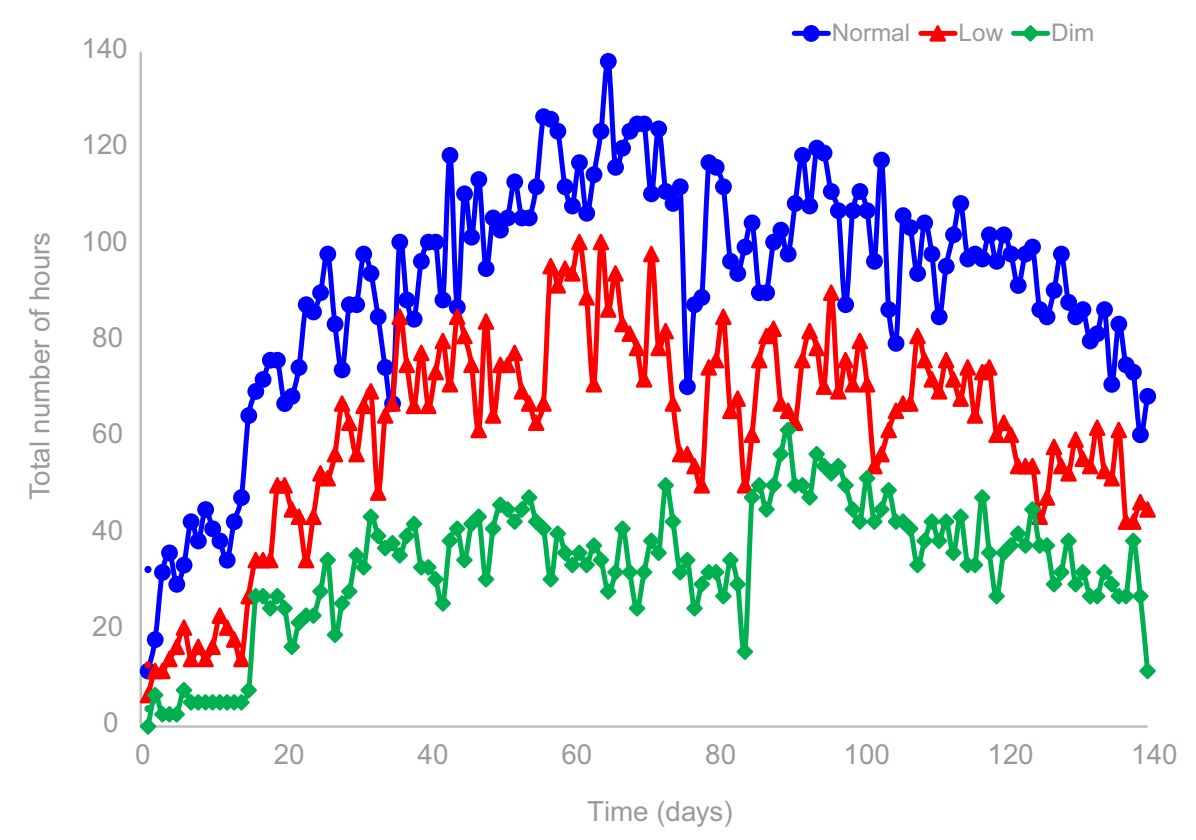

Figure 2 The amount of hours used per day (\% hours, $\mathrm{n}=29)$ for the different preset levels during the intervention period.

that the combination of being able to use "normal" lighting for reading, jigsaw puzzles and handicraft, while "cosy" lighting for watching TV and in social settings was very valuable. The importance of being able to vary the different light levels that were "just right" for different purposes was also commented, and further that the "normal" lighting improved their vision. Regarding the control system, comments were that the simple design of the preset levels was valuable, and that the wireless mode made it easy use. The participants found it very useful that lamps were controlled by one box. This made it easy to use more light because avoiding bending down, stretching or walking to reach individual light switches with a painful back or reduced mobility. Twenty-four reported they would recommend a similar system to friends. The two people who did not want to recommend the system to friends because this system could not dim the light (but had preset levels), and that the control system required extension cords to connect all the lamps to the system. After the intervention, 28 of the 29 participants wanted to keep the lamps and the control system.

\section{Discussion}

This intervention investigated how improved lighting in the living room effected abilities to perform daily activities, perception of the home lighting environment, and health-related quality of life in healthy older persons living at home. The baseline study (Stage I) ${ }^{31}$ revealed that healthy older persons overall were happy, but living in darkness, and unaware of any problems related to lighting and everyday tasks. However, this intervention showed that participants were even happier with the improved lighting levels.

The ability to perform meaningful activities (eg, IADLs) significantly improved with improved lighting in the IG. In contrast, the only change in the CG was a deterioration in the ability to perform IADLs. This is, as far as we know, the first time this has been shown in healthy older adults with normal vision. The difference can be explained by the knowledge that home lighting levels were very low before the start of the intervention, ${ }^{31}$ similar to other studies, ${ }^{27,32,45}$ and the significant improvement in lighting improved IADLs. These results are in line with previous studies in healthy older adults ${ }^{27}$ and low vision. ${ }^{38}$ The deterioration seen in the CG was not expected. One interpretation could be that the need for more lighting to compensate for normal age-related vision changes was absent in the CG, and further that they reported the ability to perform IADLs to be very easy at the start of the intervention. When ADLs become easier, one might infer that these activities are performed more often, enabling promotion of both cognitive and physical health. ${ }^{3}$

Specifically the ability to read and write improved in the IG. Reading and writing are activities that are visually demanding and require more lighting with normal age changes. Most reading tasks benefit from specific task 
lighting, but this study also shows that improving the general lighting will benefit reading. Reading is considered an important and meaningful activity for most people, not only for pleasure, but also for accessing information and promoting independence and social communication. The ability to participate in meaningful conversations with others, and feeling a part of society reduces the risk of feeling of isolated. Further, the ability to read is a good measure of vision-related quality of life, ${ }^{12,46,47}$ and reduced near vision is associated with reduction in depression and mental health. ${ }^{15,48}$

The IG reported significant improvements in the home lighting environment after the intervention, and all but one wanted to keep the lighting system after the intervention ended. This indicates that lighting positively influences the perception of the home environment, and participants were happy with the intervention. That homes are perceived as a good place to be is even more important as older persons have to remain longer at home. Further, homes have to facilitate maintaining meaningful activities, and consequently our study confirms that lighting is a factor promoting several health aspects. This was supported by free comments, where some reported that ceasing performance of certain tasks was due to reduced vision because of poor lighting in the evening. Many older persons experience a reduction in social activities, and any factor contributing to improve this is important. ${ }^{4}$ This emphasizes that lighting is an essential contributor to promote better health among older persons living at home, in line with other studies. $^{24-27}$ As such, we interpret our results to nuance and support the findings by Sörensen and Brunnström; ${ }^{27}$ that good lighting can promote health, even if we did not replicate this specifically. As our small sample consisted of healthy older adults and the intervention period was short, we did not expect a significant change in health.

The diary showed that the "normal" lighting was the preferred level during the whole period. This indicates that the "normal" lighting level quickly was adapted and perceived as helpful. Moreover, the diary showed a gradual increase in the use of more light during the darkest wintertime, before the overall use was reduced toward the end of the intervention period. The most plausible explanation for this is that the behavior is adapted to the seasonal variation in daylight during the intervention period. Interestingly, there is a marked dip for all three light levels, coinciding with the Christmas and New Year holiday period. We interpret this as an indication that participants were spending time outside their home, for example while visiting family. It further shows the compliance and diligence of the participants to log the use of light levels in their diary. Compliance is essential in order to change behavior and for a successful implementation. Compliance among older persons requires the intervention to be perceived as meaningful, simple, relatively easy to implement and improvements must be experienced relatively quickly. ${ }^{49-51}$ With this in mind, our intervention seemed to fulfill criteria for a successful outcome, where the use of more light resulted in improved function and a positive perception of the home environment. The "normal" light was throughout the intervention the most used level. One explanation is described above that it quickly helped the ability to perform activities, and that it was perceived as pleasant. Another factor could be that instructing the participants that this was the recommended "normal" lighting levels, may have influenced the rapid adaptation. A simplistic interpretation from our intervention is that by informing people of what the lighting should be, and providing the system to achieve this, will make people change their behavior - as long as they find it useful. The fact that all but one wanted to keep the lamps and control system also indicates that this simple intervention were perceived as adding something positive to the homes and that the intervention has provided a permanent change to use higher lighting levels at home, in support of other studies. ${ }^{27,38}$

Normal vision changes and increased prevalence of eye diseases with age means that older persons need more and better lighting. Lighting as an important factor in healthy aging at home was also founded by Haanes and colleagues. $^{29}$ They showed that small improvements, such as correct glasses, removal of earwax and use hearing aids, and increase the lighting levels had an encouraging effect on health in persons with a mean age of 88 years. However, their participants were too old and fragile to adapt fully to the advice given, and the authors concluded that these interventions should be applied earlier. Our study confirms that simple lighting improvements at home are wise to adapt already in the 70 s to reduce the consequences of normal age-related vision impairments. Further, it suggests that lighting is important to promote better health and well-being in older persons living at home, in agreement with other studies. ${ }^{20,23,52}$ We argue that better lighting also will reduce the risk of falls at home, as it is well documented that impaired vision increases the risk of falling. ${ }^{24-26}$ As such, it is clearly necessary for health care providers to increase their 
knowledge and competency regarding indoor lighting. This includes the ability to assess whether the home lighting is universally designed, with lamps giving light without glare, lightbulbs being easy to change, and the ability to vary the level of lighting. In addition, new lightbulbs are energy efficient, and running costs are negligible. More information about what older people know about the effects of indoor lighting on vision, ADLs, and quality of life is also required.

Our study on healthy older persons adds to the knowledge that good lighting benefits daily activities including reading in persons with normal vision. ${ }^{24,38,53}$ This confirms that lighting is an environmental characteristic positively influencing the quality of life, ${ }^{27,38}$ and should be considered in promoting healthy aging.

\section{Limitations}

Strengths of the study include that the differences in sociodemographic variables between participants were small, and did not vary from the baseline study. In addition, the sample is representative of the Norwegian population born in $1934^{54}$ with respect to the sociodemographic distribution, which we believe strengthens the potential generalizability of the study results. Another strength is the collaborative and multidisciplinary design and analysis by the multidisciplinary research group, which contribute to the validity of the results. Limitations include the confines of this basic intervention particularly when it comes to the diary entries, which might have caused a bias in the data. However, the diary logs showed that the participants were very thorough, and we believe any such biases to be small. Despite these limitations, we believe that this intervention study contributes important knowledge that may guide further research and clinical practice in this area.

\section{Conclusion}

The ability to perform meaningful activities is essential to maintain a good quality of life and facilitate healthy aging at home. This requires good vision and lighting. Our study showed that good lighting improved the ability to read and perform ADLs, and increased the home environment. Notably, improved lighting could easily be achieved with a basic low-cost control system. Our study confirms that lighting is an environmental characteristic influencing quality of life and should be considered in promoting healthy aging.

\section{Abbreviation list}

ADL, activities of daily living; IADL, instrumental activities of daily living; HPNT, health preventative nurse team; CG, control group; IG, intervention group; $\mathrm{MH}$, mental health summary scores; $\mathrm{PH}$, physical health summary scores.

\section{Ethics approval and informed consent}

All participated with written informed consent. The study was carried out in accordance with the Declaration of Helsinki, approved by the Regional Committee for Medical Research Ethics and the Ombudsman for Privacy in Research at the Norwegian Social Science Data Services.

\section{Acknowledgments}

The authors want to acknowledge emeritus professor Gunnar Horgen, associate professor Ösp Egilsdottir RN, lighting designers Benedikte Nilsen Rauan, MultiConsult Oslo, Thomas Hummel ECT AS Drammen, Mari Sando ECT AS Drammen, and members of the health promotion nursing team in Drammen municipality, Norway for the support and assistance in carrying out the project.

This study was given financial support by the Norwegian State Housing Bank, Arena Health Innovation, Elko, Mulitconsult Oslo \& ECT AS Drammen. Sponsors had no involvement in any of the stages from study design to submission of this paper for publication.

\section{Author contributions}

Study design: HKF and GE contributed to the study design. All authors contributed to data analysis, drafting or revising the article, gave final approval of the version to be published, and agree to be accountable for all aspects of the work.

\section{Disclosure}

The authors reports no conflicts of interest in this work.

\section{References}

1. Christensen K, Doblhammer G, Rau R, Vaupel JW. Ageing populations: the challenges ahead. Lancet. 2009;374(9696):1196-1208. doi:10.1016/S0140-6736(09)61460-4

2. Rechel B, Grundy E, Robine JM, et al. Ageing in the European Union. Lancet. 2013;381(9874):1312-1322. doi:10.1016/S0140-6736(12) 62087-X 
3. WHO. Global Strategy and Action Plan on Ageing and Health. Geneva: World Health Organization; 2017.

4. WHO. WHO Housing and Health Guidelines. Geneva: World Health Organization; 2018.

5. WHO. World Report on Ageing and Health. World Health Organization; 2015.

6. Falkenberg HK, Rubin GS, Bex PJ. Acuity, crowding, reading and fixation stability. Vision Res. 2007;47(1):126-135. doi:10.1016/j. visres.2006.09.014

7. Black A, Wood J. Vision and falls. Clin Exp Optom. 2005;88 (4):212-222.

8. White UE, Black AA, Wood JM, Delbaere K. Fear of falling in vision impairment. Optom Vis Sci. 2015;92(6):730-735. doi:10.1097/ OPX.0000000000000596

9. Freeman E, Muñoz B, Rubin G, West S. Visual field loss increases the risk of falls in older adults: the Salisbury eye evaluation. Invest Ophthalmol Vis Sci. 2007;48(10):4445-4450. doi:10.1167/iovs.07-0326

10. Huang HC, Gau ML, Lin WC, George K. Assessing risk of falling in older adults. Public Health Nurs. 2003;20(5):399-411.

11. Tsai S-Y, Cheng C-Y, Hsu W-M, Su T-P, Liu J-H, Chou P. Association between visual impairment and depression in the elderly. J Formos Med Assoc. 2003;102(2):86-90.

12. El-Gasim M, Munoz B, West SK, Scott AW. Associations between self-rated vision score, vision tests, and self-reported visual function in the salisbury eye evaluation study. Invest Ophthalmol Vis Sci. 2013;54(9):6439-6445.

13. Gall C, Brosel D, Sabel BA. Remaining visual field and preserved subjective visual functioning prevent mental distress in patients with visual field defects. Front Hum Neurosci. 2013;7:584. doi:10.3389/ fnhum.2013.00584

14. Renaud J, Bedard E. Depression in the elderly with visual impairment and its association with quality of life. Clin Interv Aging. 2013;8:931-943. doi:10.2147/CIA.S27717

15. van der Aa HP, Comijs HC, Penninx BW, van Rens GH, van Nispen RM. Major depressive and anxiety disorders in visually impaired older adults. Invest Ophthalmol Vis Sci. 2015;56 (2):849-854. doi:10.1167/iovs.14-15848

16. Ball K, Owsley C, Stalvey B, Roenker DL, Sloane ME, Graves M. Driving avoidance and functional impairment in older drivers. Accid Anal Prev. 1998;30(3):313-322.

17. Owsley C, McGwin G Jr. Vision and driving. Vision Res. 2010;50 (23):2348-2361. doi:10.1016/j.visres.2010.05.021

18. Brabyn JA, Schneck ME, Lott LA, Haegerstrom-Portnoy G. Night driving self-restriction: vision function and gender differences. Optom Vis Sci. 2005;82(8):755-764.

19. Houde SC, Huff MH. Age-related vision loss in older adults. A challenge for gerontological nurses. J Gerontol Nurs. 2003;29(4):25-33.

20. Shi J, Zhou BY, Tao YK, et al. Incidence and associated factors for single and recurrent falls among the elderly in an urban community of Beijing. Biomed Environ Sci. 2014;27(12):939-949. doi:10.3967/bes2014.134

21. Lopez-Soto PJ, Manfredini R, Smolensky MH, Rodriguez-Borrego MA. $24 \mathrm{hr}$ pattern of falls in hospitalized and long-term care institutionalized elderly persons: a systematic review of the published literature. Chronobiol Int. 2015;32(4):548-556. doi:10.3109/ 07420528.2014.987295

22. Crews JE, Chou CF, Stevens JA, Saaddine JB. Falls among persons aged $>/=65$ years with and without severe vision impairment - United States, 2014. Mmwr. 2016;65(17):433-437. doi:10.15585/mmwr.mm6517a2

23. Brown MJ, Jacobs DE. Residential light and risk for depression and falls: results from the LARES study of eight European cities. Public Health Rep. 2011;126(Suppl 1):131-140. doi:10.1177/ 00333549111260S117

24. Stanley P, Yuanlong L. Inadequate light levels and their effect on falls and daily activities of community dwelling older adults: a review of literature. NZ J Occup Ther. 2012;59:39-42.

25. Boyce P. Lighting for the elderly. Technol Disabil. 2003;15(3):165-180.
26. Boyce PR. Human Factors in Lighting. London: Crc Press; 2014.

27. Sörensen S, Brunnström G. Quality of light and quality of life: an intervention study among older people. Light Res Technol. 1995;27 (2):113-118. doi:10.1177/14771535950270020501

28. Haanes GG, Kirkevold M, Hofoss D, Eilertsen G. Discrepancy between self-assessments and standardised tests of vision and hearing abilities in older people living at home: an ROC curve analysis. $J$ Clin Nurs. 2015;24(23-24):3380-3388. doi:10.1111/jocn.12967

29. Haanes GG, Kirkevold M, Hofoss D, Horgen G, Eilertsen G. An intervention designed to improve sensory impairments in the elderly and indoor lighting in their homes: an exploratory randomized controlled trial. J Multidiscip Healthc. 2015;8:11-20. doi:10.2147/ JMDH.S71718

30. Hamel KA, Okita N, Higginson JS, Cavanagh PR. Foot clearance during stair descent: effects of age and illumination. Gait Posture. 2005;21(2):135-140. doi:10.1016/j.gaitpost.2004.01.006

31. Eilertsen G, Horgen G, Kvikstad TM, Falkenberg HK. Happy living in darkness! indoor lighting in relation to activities of daily living, visual and general health in 75-year-olds living at home. $J$ Hous Elderly. 2016;30(2):199-213. doi:10.1080/02763893.2016.1162256

32. Hegde AL, Rhodes R. Assessment of lighting in independent living facilities and residents' perceptions. J Appl Gerontol. 2009;29 (3):381-390

33. Campbell V, Crews J, Moriarty D, Zack M, Blackman D Surveillance for sensory impairment, activity limitation, and healthrelated quality of life among older adults-United States, 1993-1997. MMWR CDC Surveill Summ. 1999;48(8):131-156.

34. Noell-Waggoner E. Lighting solutions for contemporary problems of older adults. J Psychosoc Nurs Ment Health Serv. 2004;42(7):14-20.

35. Grandner MA, Kripke DF, Langer RD. Light exposure is related to social and emotional functioning and to quality of life in older women. Psychiatry Res. 2006;143(1):35-42. doi:10.1016/j.psychres.2005.08.018

36. De Lepeleire J, Bouwen A, De Coninck L, Buntinx F. Insufficient lighting in nursing homes. $J$ Am Med Dir Assoc. 2007;8(5):314-317. doi:10.1016/j.jamda.2007.01.003

37. Shikder S, Mourshed M, Price A. Therapeutic lighting design for the elderly: a review. Perspect Public Health. 2012;132(6):282-291. doi:10.1177/1757913911422288

38. Brunnström G, Sörensen S, Alsterstad K, Sjöstrand J. Quality of light and quality of life-the effect of lighting adaptation among people with low vision. Ophthalmic Physiol Opt. 2004;24(4):274-280. doi:10.1111/j.1475-1313.2004.00192.x

39. Lyskultur. Belysning for eldre og svaksynte [Lighting Conditions for Elderly and Visually Impaired People]. Vol. 11/97. Sandvika: Lyskultur; 1997.

40. Gitlin LN. Conducting research on home environments: lessons learned and new directions. Gerontologist. 2003;43(5):628-637.

41. Loge JH, Kaasa S. Short form 36 (SF-36) health survey: normative data from the general Norwegian population. Scand J Soc Med. 1998;26(4):250-258.

42. Ware J, Snow KK, Kosinski M. SF-36 Health Survey: Manual and Interpretation Guide. Lincon, RI: Quality Metric Incorporated; 2002.

43. Bjørset -H-H. Lysteknikk: Lys og belysning [Lighting technology: Light and lighting]. Oslo: Universitetsforlaget; 2000.

44. America IESoN. Lighting and the Visual Environment for Senior Living. New York: Illuminating Engineering Society; 2007. ANSI/ IESNA RP-28-07

45. Bakker R, Iofel Y, Lachs MS. Lighting levels in the Dwellings of homebound older adults. J Hous Elderly. 2004;18(2):17-27. doi:10.1300/J081v18n02_03

46. Hazel CA, Petre KL, Armstrong RA, Benson MT, Frost NA. Visual function and subjective quality of life compared in subjects with acquired macular disease. Invest Ophthalmol Vis Sci. 2000;41(6):1309-1315.

47. Matthews K, Nazroo J, Whillans J. The consequences of self-reported vision change in later-life: evidence from the English longitudinal study of ageing. Public Health. 2017;142:7-14. doi:10.1016/j.puhe.2016.09.034 
48. Zhang X, Bullard K, Cotch M, et al. Association between depression and functional vision loss in persons 20 years of age or older in the united states, nhanes 2005-2008. JAMA Ophthalmol. 2013;131 (5):573-581. doi:10.1001/jamaophthalmol.2013.2597

49. Dale B, Söderhamn U, Söderhamn O. Self-care ability among home-dwelling older people in rural areas in southern Norway. Scand J Caring Sci. 2012;26(1):113-122. doi:10.1111/j.14716712.2011.00917.x

50. Atreja A, Bellam N, Levy SR. Strategies to enhance patient adherence: making it simple. MedGenMed. 2005;7(1):4.

51. Bunn F, Dickinson A, Barnett-Page E, McInnes E, Horton K. A systematic review of older people's perceptions of facilitators and barriers to participation in falls-prevention interventions. Ageing Soc. 2008;28(4):449-472.
52. Bhorade AM, Perlmutter MS, Wilson B, et al. Differences in vision between clinic and home and the effect of lighting in older adults with and without glaucoma. JAMA Ophthalmol. 2013;131 (12):1554-1562. doi:10.1001/jamaophthalmol.2013.4995

53. Bowers AR, Meek C, Stewart N. Illumination and reading performance in age-related macular degeneration. Clin Exp Optom. 2001;84 (3):139-147.

54. Statistics Norway. Population Data. Statistics Norway. Available from: https://www.ssb.no/en/befolkning. 2018.

\section{Publish your work in this journal}

The Journal of Multidisciplinary Healthcare is an international, peerreviewed open-access journal that aims to represent and publish research in healthcare areas delivered by practitioners of different disciplines. This includes studies and reviews conducted by multidisciplinary teams as well as research which evaluates the results or conduct of such teams or healthcare processes in general. The journal covers a very wide range of areas and welcomes submissions from practitioners at all levels, from all over the world. The manuscript management system is completely online and includes a very quick and fair peer-review system. Visit http://www.dovepress.com/testimonials. php to read real quotes from published authors. 